(2) Open Access Full Text Article

\title{
In vitro-activated tumor-specific $T$ lymphocytes prolong the survival of patients with advanced gastric cancer: a retrospective cohort study
}

This article was published in the following Dove Press journal:

OncoTargets and Therapy

23 June 2016

Number of times this article has been viewed

Jun Kuai'

Fang Yang'

Guang-Jun $\mathrm{Li}^{2}$

Xiang-Jie Fang ${ }^{3}$

Bao-Qin $\mathrm{Gao}^{2}$

'Department of Gastroenterology,

${ }^{2}$ First Department of General Surgery,

${ }^{3}$ Second Department of General

Surgery, First Affiliated Hospital of

Xin-Xiang Medical University, Henan,

People's Republic of China
Correspondence: Fang Yang

Department of Gastroenterology, First

Affiliated Hospital of Xin-Xiang Medical University, 88 Jiankang Road, Weihui,

Henan 463000, People's Republic

of China

Tel/fax +863734402120

Email yangf880@sina.com
Background: Conventional tumor managements have limited survival benefits and cause severely impaired immune function in patients with advanced gastric cancer (GC) whereas immunotherapies could restore antitumor immunity. This prospective cohort study was aimed at investigating the efficacy of in vitro-activated tumor-specific T lymphocytes combined with chemotherapy on the survival of patients with advanced GC.

Patients and methods: Two hundred and seventy-four postoperative patients were enrolled in this study to receive either activated $\mathrm{T}$ lymphocytes immunotherapy combining chemotherapy (71 patients) or only receive postoperative chemotherapy (203 patients). Overall survival was analyzed by the Kaplan-Meier with log-rank test and Cox's regression methods.

Results: The immunotherapy prolonged 9.8-month median survival for advanced gastric cancer ( 29.70 vs 19.70 months, $P=0.036$ ). Furthermore, immunotherapy significantly benefited the survival of patients who underwent radical, palliative resection, and stage III malignancy. No serious adverse effect was observed in the immunotherapy group.

Conclusion: In vitro-activated tumor-specific $\mathrm{T}$ lymphocytes prolonged survival in patients with advanced GC.

Keywords: T lymphocytes, immunotherapy, survival, gastric cancer

\section{Introduction}

Gastric cancer (GC) is the second leading cause of cancer-related deaths worldwide and also accounts for the third highest cancer mortality rate in the People's Republic of China. ${ }^{1,2}$ Many patients with GC are diagnosed at an advanced stage because GC is characterized by frequently asymptomatic at early stages. ${ }^{3}$ Although standardized comprehensive therapies of surgical resection, adjuvant chemotherapy, and radiotherapy have been widely used for the management of patients with advanced GC, the efficacy of these therapies and the survival rates of patients with advanced GC remain low. ${ }^{4}$ Recently, immunotherapy has become a promising strategy for the treatment of several types of cancers and some immunotherapies have been approved for clinic use by the Food and Drug Administration of USA. ${ }^{5}$ However, little is known about immunotherapy for patients with advanced GC.

Various immunocytes are used for immunotherapy in cancer, such as dendritic cell (DC)-based vaccine, natural killer cells, and cytokine-induced killer cells. ${ }^{6-11}$ Many studies have tested the efficacy of adoptive transfer of these immune cells in animal models and in the clinic; however, efficacy is limited for solid cancer owing to tumor specific lacking of immune cells. ${ }^{12}$ Therefore, development of a more tumor-specific 
immunotherapy approach for preventing cancer metastasis and recurrence after surgery is required for further promoting the survival of advanced GC patients.

$\mathrm{T}$ lymphocytes activated through tumor lysate-pulsed autologous DC cells can induce more specific antitumor immunity against the resident tumor cells after treatment and provide more effective therapeutic effect: ${ }^{13}$ otherwise, patients suffer severe immunosuppression within 7-14 days after surgery. ${ }^{14}$ Administration of $\mathrm{T}$ lymphocytes during the perioperative period may restore antitumor immunity as soon as possible and thus inhibit metastasis and recurrence. Patients with advanced GC have susceptibility to local recurrence, peritoneal implantation, and hematogenous metastasis. Administration of $\mathrm{T}$ lymphocytes via intravenous and intraperitoneal approaches may have more comprehensive effects on metastasis and recurrence. In this study, a single-center prospective clinical trial was performed to validate the efficacy and safety of postoperative immunotherapy with in vitro-activated $\mathrm{T}$ lymphocytes for patients with advanced GC through various therapeutic approaches at different postoperative treatment points.

\section{Patients and methods}

\section{Patients}

Two hundred and seventy-four patients who had undergone surgery for primary GC at the First Affiliated Hospital of XinXiang Medical University from June 2, 2010 to July 1, 2014 were recruited in this study, including 71 patients who received chemotherapy and multi-immunocytes treatment in the immunotherapy group. Two hundred and three patients who received chemotherapy alone within the corresponding period were enrolled as the control group. Inclusion criteria were histologically confirmed stage III or IV GC, over 18 years of age, and a life expectancy of $>24$ weeks. The exclusion criteria were acute and severe postoperative complications, active uncontrolled infection, acute and chronic comorbidities, and death due to other causes. Written informed consent was obtained from individual patients. The study protocol was approved by the Institute Review Board of the Xin-Xiang Medical University.

\section{Treatment}

According to the 2014 National Comprehensive Cancer Network clinical practice guidelines in oncology, all patients in this study were treated with standard curative resection and postoperative standard chemotherapeutic regimens, including epirubicin, cisplatin, and 5-fluorouracil or docetaxel, cisplatin, and 5-fluorouracil. A total of 77 patients in the immunotherapy group received postoperative immunotherapy within 14 days after surgery, and immunocytes were administrated after every two cycles of chemotherapy. Peripheral blood mononuclear cells (PBMCs) were isolated from peripheral blood of patients for preparing $\mathrm{T}$ lymphocytes. Individual patients were sequentially administrated one part of $\mathrm{T}$ lymphocytes $\left(>1 \times 10^{10}\right)$ via the intraperitoneal approach on day 12 after PBMC collection and were intravenously transfused with the remaining part $\left(>1 \times 10^{10}\right)$ after PBMC collection.

\section{Follow-up}

All the patients were followed up as outpatients, including physical examination and serum carcinoembryonic antigen test every 3 months for the first 2 years, every 6 months for the next 3 years, and once annually thereafter. Endoscopy or abdominal computerized tomography scans were obtained generally every 12 months. Clinical follow-up duration lasted from the date of surgery to either the time of death or July 2015.

\section{Generation of activated T lymphocytes}

Tumor samples of individual patients obtained during the surgery were mechanically dispersed to create a single-cell suspension, then incubated in a water bath at $60^{\circ} \mathrm{C}$ for 60 minutes to induce heat shock proteins. After three cycles of $-80^{\circ} \mathrm{C}$ freeze/thaw, the cells were centrifuged at $4^{\circ} \mathrm{C}, 600 \times g$ for 60 minutes. The supernatants were filtrated through a $0.2 \mu \mathrm{m}$ filter, and the concentrations of proteins in the supernatants were determined as tumor-specific antigens, which were stored at $-80^{\circ} \mathrm{C}$ until use.

PBMCs at $6 \times 10^{6}$ cells $/ \mathrm{mL}$ were isolated from the blood of individual patients by Ficoll-Hypaque (Haoyang Biological Manufacture, Tianjin, People's Republic of China) gradient centrifugation and then cultured at $37^{\circ} \mathrm{C}$ for 3 hours. Tumor lysate-loaded DCs were generated by the routine method from the adherent PBMCs. ${ }^{15,16}$ The nonadherent PBMCs $\left(1 \times 10^{5}\right.$ cells $\left./ \mathrm{mL}\right)$ were stimulated with anti-CD3 $(20 \mu \mathrm{g} / \mathrm{mL})$ in the presence of recombinant human interferon gamma $(200 \mathrm{U} / \mathrm{mL})$ and recombinant human interleukin-2 $(200 \mathrm{U} / \mathrm{mL})$ in T-cell media for 7 days. On day 8 , the activated $\mathrm{T}$ lymphocytes $\left(1 \times 10^{6} / \mathrm{mL}\right)$ were cultured with $1 \times 10^{7} / \mathrm{mL}$ of tumor lysate-pulsed DCs in Cellix 602 media (Xinminglitai Biological Manufacture, Beijing, People's Republic of China) for 4 days to generate activated tumor-specific T lymphocytes.

\section{Quality and sterility control of the T lymphocytes}

$\mathrm{T}$ lymphocytes were evaluated by flow cytometry using the FACSCalibur (Becton, Dickinson and Company, NJ, USA) flow cytometer before transferring to the patient. Briefly, cell samples were stained with different fluorescence-labeled antibodies 
againstCD80/CD83/D86/HLA-DR forDCs and CD3/CD4/CD8/ CD56 for T lymphocytes. Only cells with a viability of $>95 \%$ were used for treatment. To reduce the potential risk of microbial contamination, all samples of the isolated and prepared cells were sent to a microbiology laboratory for analysis of potential organism contamination.

\section{Statistical analysis}

Data were analyzed using SPSS software (version 20.0, IBM Corporation, Armonk, NY, USA). Overall survival was defined as duration from the date of surgery to death, whereas recurrencefree survival was defined as the period from the date of surgery to recurrence. The chi-square test or Fisher's exact test was used to compare different clinicopathologic characteristics between the two groups. Kaplan-Meier method was used to assess the effect of treatment on the 12- and 36-month survival rates, median survival time, and median follow-up time. The difference of 12- and 36-month survival rates between the immunotherapy and the control groups was analyzed using the chi-square test. The Cox regression model was used to assess the hazard ratio (HR) and multivariate analysis. A $P$-value of $<0.05$ was considered statistically significant.

\section{Results}

\section{Patients}

A total of 274 patients, including 71 patients in the immunotherapy group and 203 in the control group, comprising
192 males and 82 females with an average age of $54 \pm 11.8$ years were studied. Among these patients, 72 cases were diagnosed with gastric cardia cancer, whereas 130 patients presented as tumor located in the gastric body and 72 patients with gastric antrum cancer. According to the tumor-node-metastasis staging methods, 185 patients were stage III and 89 patients were stage IV. Moreover, 119 patients underwent radical resection, while 155 patients received palliative surgery. As expected, there was no significant difference in the distribution of age, sex, tumor site and size, pathologic differentiation, clinical stage, and surgical mode between the immunotherapy and control groups (Table 1).

\section{Quantity and quality of activated T lymphocytes and tumor lysate-loaded DCs}

Median cell count of DCs has been achieved to approximately $4 \times 10^{7}\left(0.2-8.0 \times 10^{7}\right)$ cells $/ \mathrm{mL}$ after culturing in vitro for 8 days. Subsequently, phenotypic analysis of DCs showed that the median percentages (and range) of $\mathrm{CD} 80^{+}, \mathrm{CD} 83^{+}$, $\mathrm{CD}^{2} 6^{+}$, and HLA-DR ${ }^{+}$DCs were $86.52 \%(62.13 \%-97.54 \%)$, $72.48 \%$ (56.48\%-97.66\%), 88.64\% (72.38\%-98.33\%), and $92.84 \%(80.12 \%-97.24 \%)$, respectively (Figure 1A). The median number of the available $\mathrm{T}$ lymphocytes was $4.57 \times 10^{10}$ $\left(0.8-8.7 \times 10^{10}\right)$. Furthermore, median percentages (and range) of $\mathrm{CD}^{+}{ }^{+} \mathrm{CD}^{+}{ }^{+} \mathrm{T}$-cells and $\mathrm{CD} 3{ }^{+} \mathrm{CD} 56^{+}$natural killer T-cells of $\mathrm{T}$ lymphocytes were $71.02 \%(62.13 \%-88.14 \%)$ and $34.62 \%(6.73 \%-48.57 \%)$, respectively (Figure 1B).

Table I Baseline demographic and clinical characteristics of advanced gastric cancer patients

\begin{tabular}{|c|c|c|c|}
\hline Characteristic & Control, $\mathrm{N}=203$; n (\%) & Immunotherapy, N=7 I; n (\%) & $P$-value \\
\hline \multicolumn{4}{|l|}{ Age (years) } \\
\hline Mean & 57 & 54 & \\
\hline Minimum & 23 & 32 & \\
\hline Maximum & 86 & 75 & \\
\hline Sex & & & 0.114 \\
\hline Male & $137(67.5)$ & $55(77.5)$ & \\
\hline Female & $66(32.5)$ & $16(22.5)$ & \\
\hline Tumor site & & & 0.506 \\
\hline Gastric cardia & $50(24.6)$ & $22(31.0)$ & \\
\hline Gastric body & $100(49.2)$ & $30(42.3)$ & \\
\hline Gastric antrum & $53(26.2)$ & $19(26.7)$ & \\
\hline Tumor size $(\mathrm{cm})$ & & & 0.498 \\
\hline$<5$ & $140(69.0)$ & $52(73.2)$ & \\
\hline$\geq 5$ & $63(31.0)$ & $19(26.8)$ & \\
\hline Differentiation & & & 0.746 \\
\hline Well/moderate & $116(57.1)$ & $39(54.9)$ & \\
\hline Poor & $87(42.9)$ & $32(45.1)$ & \\
\hline Clinical stage & & & 0.568 \\
\hline III & $139(68.5)$ & $46(64.8)$ & \\
\hline IV & $64(3 \mid .5)$ & $25(35.2)$ & \\
\hline Surgical procedure performed & & & 0.816 \\
\hline Radical & $89(43.8)$ & $30(42.3)$ & \\
\hline Palliative & $114(56.2)$ & $4 \mid(57.7)$ & \\
\hline
\end{tabular}



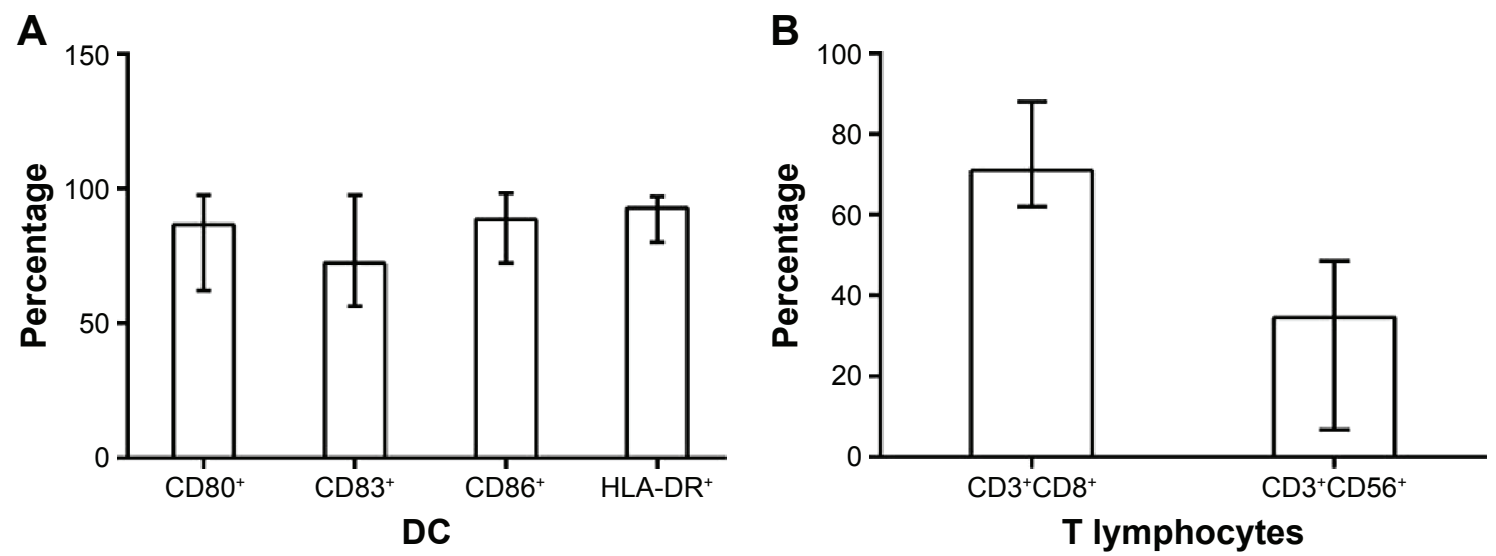

Figure I Phenotypic analysis of DC and T-cells.

Notes: (A) Percentages (and range) of CD80+, CD83+, CD86+, and HLA-DR+ DCs were 86.52\% (62.13\%-97.54\%), 72.48\% (56.48\%-97.66\%), 88.64\% (72.38\%-98.33\%), and $92.84 \%$ (80.12\%-97.24\%), respectively. (B) Median percentages (and range) of CD3 ${ }^{+} \mathrm{CD}^{+} \mathrm{T}$-cells and CD3 ${ }^{+} \mathrm{CD} 56^{+} \mathrm{NKT}$ cells of T lymphocytes were $71.02 \%(62.13 \%-88.14 \%$ ) and $34.62 \%(6.73 \%-48.57 \%)$.

Abbreviations: DC, dendritic cell; NKT, natural killer T-cells; HLA-DR, human leukocyte antigen-DR.

\section{Treatment efficacy}

Median follow-up duration was 16.4 months(6.1-79.57 months). At the end of this study, 184 (67.15\%) of the 274 patients had died. Upon assessing the efficacy of available T lymphocytes for advanced GC, we found that patients in the immunotherapy group had a statistically significantly better postoperative prognosis than those in the control group with respect to overall median survival (29.70 vs 19.70 months, $P=0.036$ ) (Table 2; Figure 2). Otherwise, the clinical stage and surgical procedure also significantly influenced the prognosis of advanced GC (Table 2).

Tumor burden has been considered as an obvious factor influencing antitumor immune status. For patients who undergo palliative surgery, immunotherapy can prolong median

Table 2 The prognostic characteristics of advanced gastric cancer patients

\begin{tabular}{|c|c|c|c|c|c|c|}
\hline \multirow[t]{2}{*}{ Characteristics } & \multicolumn{3}{|c|}{ Univariate } & \multicolumn{3}{|c|}{ Multivariate } \\
\hline & $\mathbf{n}$ & MS (months) & $P$-value & HR & $95 \% \mathrm{Cl}$ & $P$-value \\
\hline Age (years) & & & 0.624 & & & \\
\hline$\geq 60$ & 190 & 21.13 & & & & \\
\hline$<60$ & 84 & 22.33 & & & & \\
\hline Sex & & & 0.632 & & & \\
\hline Male & 192 & 19.27 & & & & \\
\hline Female & 82 & 26.80 & & & & \\
\hline Tumor site & & & 0.136 & & & \\
\hline Gastric cardia & 72 & 20.17 & & & & \\
\hline Gastric body & 130 & 22.52 & & & & \\
\hline Gastric antrum & 72 & 10.38 & & & & \\
\hline Tumor size $(\mathrm{cm})$ & & & 0.370 & & & \\
\hline$\geq 5.0$ & 192 & 20.52 & & & & \\
\hline$<5$ & 82 & 22.40 & & & & \\
\hline Differentiation & & & 0.502 & & & \\
\hline Well/moderate & 155 & 22.87 & & & & \\
\hline Poor & 119 & 21.13 & & & & \\
\hline Clinic stage & & & 0.000 & 2.201 & $1.605-3.020$ & 0.000 \\
\hline III & 185 & 26.43 & & & & \\
\hline IV & 89 & 14.27 & & & & \\
\hline Surgical procedure & & & 0.001 & 0.548 & $0.403-0.745$ & 0.000 \\
\hline Radical & 119 & 29.70 & & & & \\
\hline Palliative & 155 & 18.07 & & & & \\
\hline Immunotherapy & & & 0.036 & $0.64 I$ & $0.450-0.913$ & 0.014 \\
\hline Yes & 71 & 29.70 & & & & \\
\hline No & 203 & 19.90 & & & & \\
\hline
\end{tabular}

Abbreviations: $\mathrm{Cl}$, confidence interval; $\mathrm{HR}$, hazard ratio; $\mathrm{MS}$, median survival. 


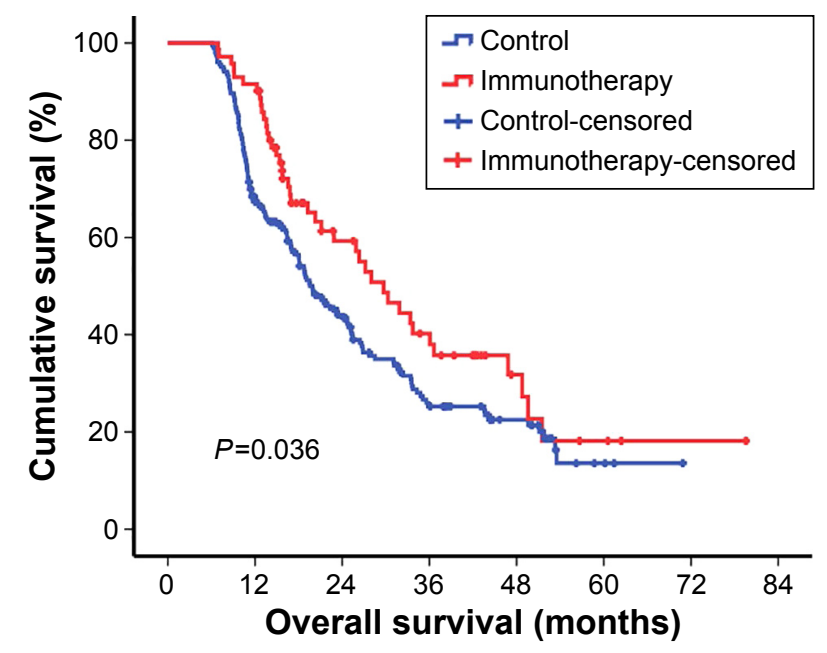

Figure 2 Kaplan-Meier estimates of overall survival.

Notes: Panel shows the results of the analysis of efficacy of immunotherapy compared with control (median survival in immunotherapy, 29.70 months; in control, 19.90 months; $P=0.036$ )

survival by 9.4 months (immunotherapy, 26.33 months; control, 16.93 months, $P=0.011)$. Similarly, patients who received immunotherapy had a longer median survival than patients in the control group after radical resection (36.63 vs 25.17 months, $P=0.024)$. Furthermore, in the univariate analysis of recurrence-free survival in patients who underwent radical resection, patients who received immunotherapy had a better outcome than patients in the control group (30.00 vs 23.14 months, $P=0.042$ ) (Figure 3).

When the influence of immunotherapy on stage II and IV GC were respectively accessed, we found that patients with stage III GC benefited from immunotherapy, showing a median survival of 36.63 months, which was longer than the control group (24.47 months, $P=0.034)$. However, there was no significant difference between the immunotherapy and control groups in patients with stage IV GC (Figure 4).

A multivariate analysis of age and sex of patients, tumor size and site, histological differentiation type, clinical stage, surgery, and immunotherapy using the Cox regression model to identify independent prognostic factors for advanced GC was performed. The result showed that immunotherapy (HR, $0.641 ; 95 \%$ confidence interval [CI], 0.450-0.913; $P<0.05$ ), surgery (HR, $0.548 ; 95 \% \mathrm{CI}, 0.403-0.745 ; P<0.05)$, and clinic stage (HR, 2.201; 95\% CI, 1.605-3.020; $P<0.05$ ) were the independent prognostic factors (Table 2).

\section{Adverse effects}

There was no obvious serious adverse effect observed in 71 patients during immunotherapy, such as high fever, chills, or allergic reactions. Five patients presented with transient fever (not more than $38.5^{\circ} \mathrm{C}$ ) after intravenous $\mathrm{T}$ lymphocytes. Two patients complained of tenesmus after intraperitoneal $\mathrm{T}$ lymphocytes and recovered without interventions.

\section{Discussion}

$\mathrm{GC}$ is a common form of cancer and one of the most frequent causes of cancer-related deaths in the world. ${ }^{17}$ Although efficacy of GC had been promoted by multiple disciplinary team (MDT) approach, many GC patients suffer from

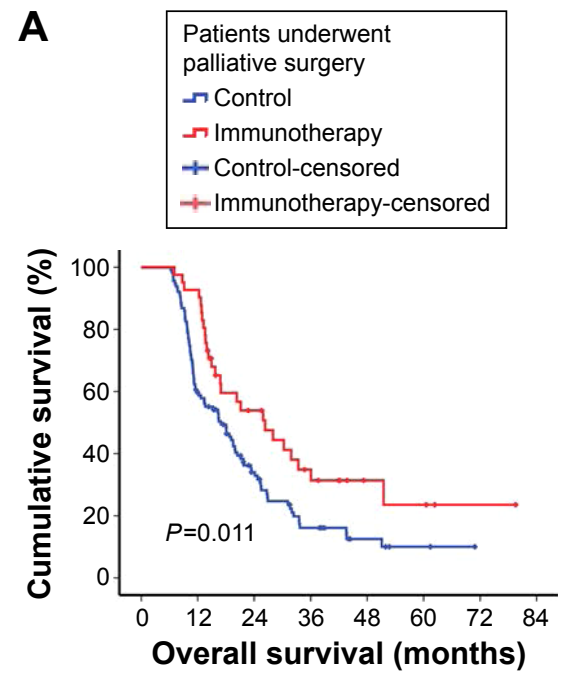

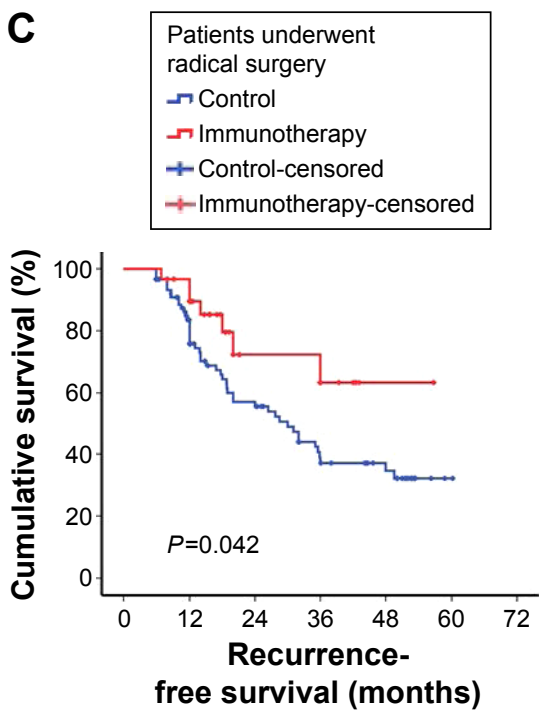

Figure 3 Survival estimation in different surgery methods.

Notes: (A) The results of the comparison analysis of the immunotherapy and control group of patients who received palliative resection (mean survival time immunotherapy, 26.33 months; in control, 16.93 months, $P=0.01$ I). (B) Similarity trend in patients who underwent radical surgery ( 36.63 vs 25.17 months, $P=0.024)$. (C) Patients who received immunotherapy had a better survival benefit than controls in the radical resection group ( 30.00 vs 23.14 months, $P=0.042)$. 

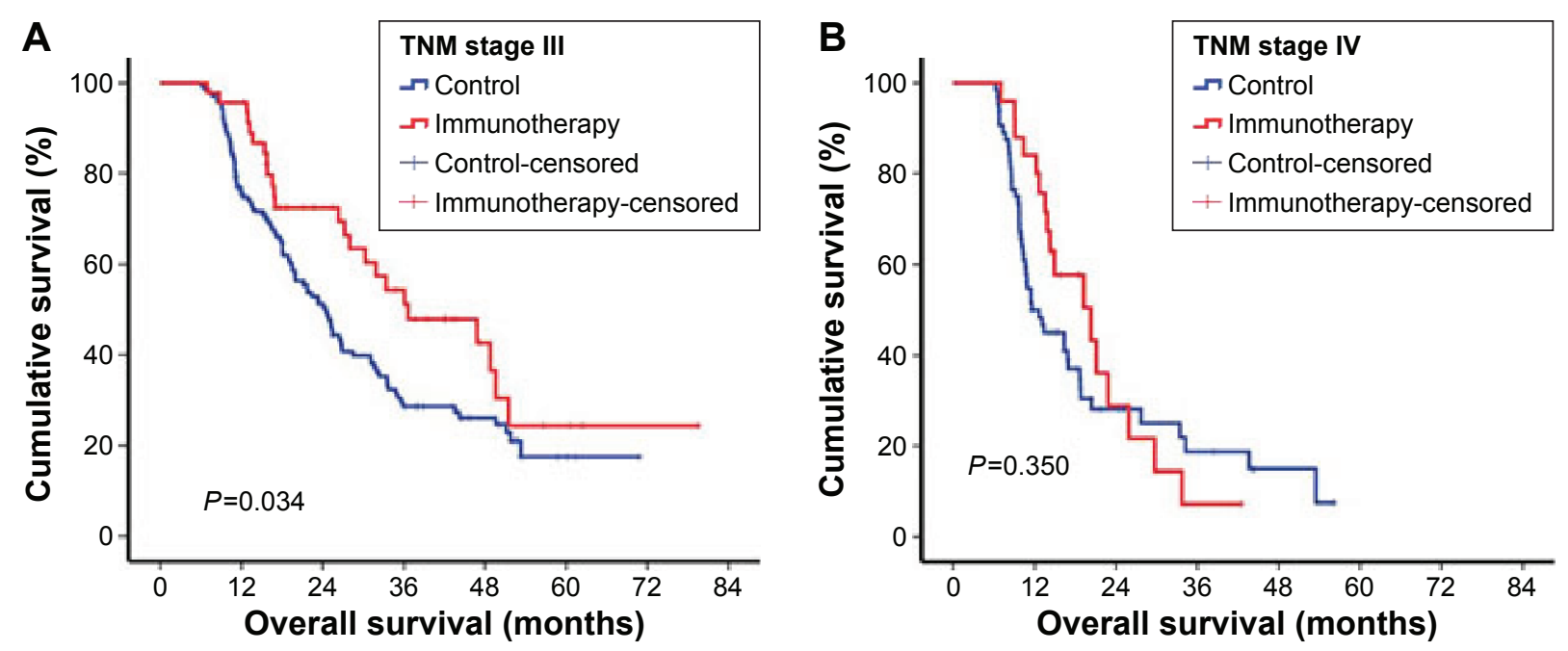

Figure 4 TNM stage-wise survivability.

Notes: (A) There was a statistically significant survival difference between immunotherapy and control group in stage III gastric cancer patients (median survival in immunotherapy, 36.63 months; in control, 24.47 months; $P=0.034)$. (B) There was no significant survival difference between immunotherapy and control groups in stage IV gastric cancer patients (mean survival time in immunotherapy, 20.30 months; in control, 11.60 months; $P=0.350$ ).

Abbreviation: TNM, tumor-node-metastasis.

poor prognosis owing to relapse or metastasis, especially for advanced tumors. ${ }^{18}$ Conventional treatments, including surgery, chemotherapy, and radiotherapy, may induce a variety of adverse effects and impair the antitumor immunity, thus making tumor residue. ${ }^{19}$ It has been proposed that adoptive cellular immunotherapy can stimulate and restore the host antitumor immunity, which has the ability to recognize and kill tumor cells. ${ }^{20-22}$ Several adoptive cellular immunotherapies have been used in the treatment of solid tumors with increased efficacy, particularly in malignancy with poor response to traditional therapies. ${ }^{5,8,11,23}$

In this study, in vitro-activated tumor-specific T lymphocytes immunotherapy plus chemotherapy after surgery prolonged the median survival of advanced GC patients by 9.8 months compared with chemotherapy alone. There are a variety of factors determining the clinical outcome of immunotherapies for GC patients. ${ }^{24,25}$ First, the immunogenicity of tumor antigens and effective presentation of antigens play an important role in antitumor immunity. It has been proposed that tumor lysate-loaded DCs can present tumor antigen to effective $\mathrm{T}$ cells immunity in humans and rodents. ${ }^{26,27}$ For this consideration, we obtain autologous tumor samples during surgery, which was further prepared to tumor lysate. We then used prepared tumor lysate as tumor-specific antigen activating DCs. Second, the quantity and quality of immunocytes are crucial factors impacting the efficacy of immunotherapy. ${ }^{28}$ We have set up an optimal cell culture system in our laboratory and can effectively expand $\mathrm{T}$ lymphocytes, which comprised $71.02 \% \mathrm{CD} 8^{+} \mathrm{T}$-cells and $34.62 \%$ natural killer
T-cells. These cells have high immune activity and antitumor specificity. ${ }^{29,30}$ Otherwise, we can incubate tumor samples at $60^{\circ} \mathrm{C}$ for 60 minutes to induce heat shock proteins, which act as the immunologic adjuvant in tumor antigen delivery and enhance proliferation and immunological activity of T lymphocytes. ${ }^{31-33}$ Finally, a more accurate administration timing and approach can promote the efficacy of immunotherapy. There always exists an immunosuppressed status after surgery and chemotherapy, so residual tumor cells may escape immune surveillance and survive during this period. In this study, we administered $\mathrm{T}$ lymphocytes on days 12 and 14 after surgery or recovery interval among chemotherapies, which can correct such immunosuppressed status and restore antitumor immunity within a short period of time, killing residual tumor cells and inhibiting recurrent and metastatic diseases. Tumors can metastasize via peritoneal implantation and hematogenous spread, so we administrated T lymphocytes through the intravenous and intraperitoneal approaches, which may efficiently prevent local relapse and metastatic diseases.

Surgery can reduce tumor burden as much as possible, thus promoting survival, however, it also impaired anti-tumor immunity. ${ }^{34}$ Treatment with immunocytes can correct immunosuppression status after surgery. Our results coincide with these findings; immunotherapy has been shown to provide survival benefits for patients who have undergone radical surgery. In patients with residual tumor burden after palliative surgery, immunotherapy can also kill and limit the development of tumor cells, thus improving the prognosis outcome. 
In this study, we found that there was no significant difference between immunotherapy and control groups of patients with stage IV GC. The underlying reason may be that the observational duration for patients with stage IV GC was too short to obtain a statistically significant difference.

\section{Limitations}

There are several limitations in this study. First, the patients were enrolled from a single center, which cannot be applied universally. A multicenter prospective study is required for confirming the general effects of immunotherapy. Second, some unknown potential factors influence random choice of treatment regimens and affect conclusion, which may be corrected partly through Cox model analysis. Otherwise, a randomized trial should be conducted to further evaluate the benefit of immunotherapy. Lastly, the number of cases also limits the quality of further evaluating the significance of immunotherapy in stage IV patients.

\section{Conclusion}

$\mathrm{T}$ lymphocytes immunotherapy plus chemotherapy after surgery benefited patients with advanced GC. However, there are several questions that need to be resolved in further studies. These include 1) how to regulate the phenotype and the number of expanded T-cells individually for different patients; 2) how to make T-cells survive longer after infusion; and 3) how to improve tumor microenvironment and systemic environment to promote efficacy of T lymphocytes. By this way, immunotherapy would be considered as an adjuvant treatment for GC.

\section{Disclosure}

The authors report no conflicts of interest in this work. This study was funded by the authors.

\section{References}

1. Herszenyi L, Tulassay Z. Epidemiology of gastrointestinal and liver tumors. Eur Rev Med Pharmacol Sci. 2010;14(4):249-258.

2. Chen W. Cancer statistics: updated cancer burden in China. Chin J Cancer Res. 2015;27(1):1

3. Maconi G, Manes G, Porro GB. Role of symptoms in diagnosis and outcome of gastric cancer. World J Gastroenterol. 2008;14(8):1149-1155.

4. Lee JH, Kim KM, Cheong JH, Noh SH. Current management and future strategies of gastric cancer. Yonsei Med J. 2012;53(2):248-257.

5. Cheever MA, Higano CS. PROVENGE (Sipuleucel-T) in prostate cancer: the first FDA-approved therapeutic cancer vaccine. Clin Cancer Res. 2011; 17(11):3520-3526.

6. Kantoff PW, Higano CS, Shore ND, et al. Sipuleucel-T immunotherapy for castration-resistant prostate cancer. N Engl J Med. 2010;363(5):411-422.

7. Tamir A, Basagila E, Kagahzian A, et al. Induction of tumor-specific T-cell responses by vaccination with tumor lysate-loaded dendritic cells in colorectal cancer patients with carcinoembryonic-antigen positive tumors. Cancer Immunol Immunother. 2007;56(12):2003-2016.
8. Mann DL, Celluzzi CM, Hankey KG, Harris KM, Watanabe $\mathrm{R}$, Hasumi K. Combining conventional therapies with intratumoral injection of autologous dendritic cells and activated $\mathrm{T}$ cells to treat patients with advanced cancers. Ann N Y Acad Sci. 2009;1174:41-50.

9. Thanendrarajan S, Nowak M, Abken H, Schmidt-Wolf IG. Combining cytokine-induced killer cells with vaccination in cancer immunotherapy: more than one plus one? Leuk Res. 2011;35(9):1136-1142.

10. Mesiano G, Todorovic M, Gammaitoni L, et al. Cytokine-induced killer (CIK) cells as feasible and effective adoptive immunotherapy for the treatment of solid tumors. Expert Opin Biol Ther. 2012;12(6): 673-684.

11. Hunder NN, Wallen H, Cao J, et al. Treatment of metastatic melanoma with autologous $\mathrm{CD}^{+} \mathrm{T}$ cells against NY-ESO-1. $\mathrm{N}$ Engl $\mathrm{J}$ Med. 2008; 358(25):2698-2703.

12. Klebanoff CA, Acquavella N, Yu Z, Restifo NP. Therapeutic cancer vaccines: are we there yet? Immunol Rev. 2011;239(1):27-44.

13. Yang S, Gattinoni L, Liu F, et al. In vitro generated anti-tumor T lymphocytes exhibit distinct subsets mimicking in vivo antigen-experienced cells. Cancer Immunol Immunother. 2011;60(5):739-749.

14. Rybojad P, Jablonka A, Wilczynska B, Tabarkiewicz J. Surgery decreases number of cells secreting cytotoxic mediators and increases secretion of interleukin 10 in patients with lung cancer. Eur J Surg Oncol. 2013;39(11):1269-1277.

15. Nestle FO, Alijagic S, Gilliet M, et al. Vaccination of melanoma patients with peptide- or tumor lysate-pulsed dendritic cells. Nat Med. 1998;4(3):328-332.

16. Jonuleit H, Kuhn U, Muller G, et al. Pro-inflammatory cytokines and prostaglandins induce maturation of potent immunostimulatory dendritic cells under fetal calf serum-free conditions. Eur J Immunol. 1997;27(12):3135-3142.

17. Siegel R, Naishadham D, Jemal A. Cancer statistics, 2013. CA Cancer J Clin. 2013;63(1):11-30.

18. Choi YY, Noh SH, Cheong JH. Evolution of gastric cancer treatment: from the golden age of surgery to an era of precision medicine. Yonsei Med J. 2015;56(5):1177-1185.

19. Lee K, Hwang H, Nam KT. Immune response and the tumor microenvironment: how they communicate to regulate gastric cancer. Gut Liver. 2014;8(2):131-139.

20. Lu PH, Negrin RS. A novel population of expanded human $\mathrm{CD}^{+} \mathrm{CD} 56^{+}$ cells derived from $\mathrm{T}$ cells with potent in vivo antitumor activity in mice with severe combined immunodeficiency. J Immunol. 1994; 153(4):1687-1696.

21. Schmidt-Wolf GD, Negrin RS, Schmidt-Wolf IG. Activated T cells and cytokine-induced CD3 ${ }^{+}$CD56 ${ }^{+}$killer cells. Ann Hematol. 1997;74(2): $51-56$.

22. Tang X, Liu T, Zang X, et al. Adoptive cellular immunotherapy in metastatic renal cell carcinoma: a systematic review and meta-analysis. PLoS One. 2013;8(5):e62847.

23. Du XH, Liu HL, Li L, et al. Clinical significance of immunotherapy with combined three kinds of cells for operable colorectal cancer. Tumour Biol. 2015;36(7):5679-5685.

24. Stroncek DF, Berger C, Cheever MA, et al. New directions in cellular therapy of cancer: a summary of the summit on cellular therapy for cancer. J Transl Med. 2012;10:48.

25. Rosenberg SA. Raising the bar: the curative potential of human cancer immunotherapy. Sci Transl Med. 2012;4(127):127ps8.

26. Bonifaz LC, Bonnyay DP, Charalambous A, et al. In vivo targeting of antigens to maturing dendritic cells via the DEC-205 receptor improves T cell vaccination. $J$ Exp Med. 2004;199(6):815-824.

27. Galea-Lauri J, Wells JW, Darling D, Harrison P, Farzaneh F. Strategies for antigen choice and priming of dendritic cells influence the polarization and efficacy of antitumor T-cell responses in dendritic cellbased cancer vaccination. Cancer Immunol Immunother. 2004;53(11): 963-977.

28. Goldberg JL, Sondel PM. Enhancing cancer immunotherapy via activation of innate immunity. Semin Oncol. 2015;42(4):562-572. 
29. Tietze JK, Wilkins DE, Sckisel GD, et al. Delineation of antigenspecific and antigen-nonspecific $\mathrm{CD} 8\left(^{+}\right)$memory T-cell responses after cytokine-based cancer immunotherapy. Blood. 2012;119(13): 3073-3083.

30. Prado-GarciaH, Romero-Garcia S, Aguilar-Cazares D, Meneses-Flores M, Lopez-Gonzalez JS. Tumor-induced CD8 ${ }^{+} \mathrm{T}$-cell dysfunction in lung cancer patients. Clin Dev Immunol. 2012;2012:741741.

31. Srivastava P. Roles of heat-shock proteins in innate and adaptive immunity. Nat Rev Immunol. 2002;2(3):185-194.

32. Li Z, Menoret A, Srivastava P. Roles of heat-shock proteins in antigen presentation and cross-presentation. Curr Opin Immunol. 2002;14(1): 45-51.
33. Huang CX, Yu H, Yang GG, et al. [Antitumor therapeutic effect induced by intestine-carcinoma cells vaccine expressing membrane-bound heat shock protein 70]. Zhonghua Wei Chang Wai Ke Za Zhi. 2005; 8(3):255-258. Chinese [with English abstract].

34. Cuschieri A, Weeden S, Fielding J, et al. Patient survival after D1 and D2 resections for gastric cancer: long-term results of the MRC randomized surgical trial. Surgical Co-operative Group. Br J Cancer. 1999; 79(9-10):1522-1530.

\section{Publish your work in this journal}

OncoTargets and Therapy is an international, peer-reviewed, open access journal focusing on the pathological basis of all cancers, potential targets for therapy and treatment protocols employed to improve the management of cancer patients. The journal also focuses on the impact of management programs and new therapeutic agents and protocols on

\section{Dovepress}

patient perspectives such as quality of life, adherence and satisfaction. The manuscript management system is completely online and includes a very quick and fair peer-review system, which is all easy to use. Visit http://www.dovepress.com/testimonials.php to read real quotes from published authors.

Submit your manuscript here: http://www.dovepress.com/oncotargets-and-therapy-journal 